\title{
Patterns of rDNA chromosomal localization in Palearctic Cephalota and Cylindera (Coleoptera: Carabidae: Cicindelini) with different numbers of $\mathrm{X}$-chromosomes
}

\author{
Sonia J. R. Proença', Artur R. M. Serrano', José Serrano², José Galián² \\ I Centro de Biologia Ambiental /Departamento de Biologia Animall, Faculdade de Ciências, Universidade de \\ Lisboa, Campo Grande, Bloco C2 - $3^{\circ}$ Piso, 1700 Lisboa, Portugal 2 Departamento de Zoología y Antropología \\ Física, Campus de Espinardo, Universidad de Murcia, 30100 Murcia, Spain \\ Corresponding author: José Galián (jgalian@um.es) \\ Academic editor: Robert Angus | Received 27 January 2011 | Accepted 15 March 2011 | Published 5 May 2011 \\ Citation: Proença SJR, Serrano ARM, Serrano J, Galián J (2011) Patterns of rDNA chromosomal localization in \\ Palearctic Cephalota and Cylindera (Coleoptera: Carabidae: Cicindelini) with different numbers of X-chromosomes. \\ Comparative Cytogenetics 5(1): 47-59. doi: 10.3897/compcytogen.v5i1.962
}

\begin{abstract}
The ribosomal clusters of six Paleartic taxa belonging to the tiger beetle genera Cephalota Dokhtourow, 1883 and Cylindera Westwood, 1831, with multiple sex chromosomes (XXY, XXXY and XXXXY) have been localised on mitotic and meiotic cells by fluorescence in situ hybridization (FISH), using a PCRamplified $18 \mathrm{~S}$ rDNA fragment as a probe. Four patterns of rDNA localization in these tiger beetles were found: 1. Two clusters located in one autosomal pair; 2. Two clusters located in one autosomal pair and one in an X chromosome; 3. Three clusters located in three heterosomes (XXY); 4. Two clusters located in one autosomal pair and two in the heterosomes (one of the Xs and the $\mathrm{Y}$ ). These results illustrate that ribosomal cistrons have changed their number and localization during the evolution of these genera, showing a dynamic rather than a conservative pattern. These changes in rDNA localization are uncoupled with changes in the number of autosomes and/or heterosomes. A mechanism that involves transposable elements that carry ribosomal cistrons appears to be the most plausible explanation for these dynamics that involve jumping from one location in the genome to another, in some cases leaving copies in the original location.
\end{abstract}

\section{Keywords}

Cephalota, Cylindera, Cicindelini, Coleoptera, FISH, ribosomal genes, chromosome evolution

Copyright S.J.R. Proença et al. This is an open access article distributed under the terms of the Creative Commons Attribution License, which permits unrestricted use, distribution, and reproduction in any medium, provided the original author and source are credited. 


\section{Introduction}

Often closely related species differ in their karyotypes, both in terms of changes in chromosome number and morphology and/or localization of genes in chromosomes. Whether these changes have played a significant role as isolation mechanisms in speciation (White 1978; King 1993), or have been an accompanying consequence of this isolation (Futuyma and Mayer 1980; Coyne and Orr 2004) has generated some debate among cytogeneticists. It is accepted that chromosomal rearrangements reduce gene flow between populations (Spirito 1998) by reducing fitness of chromosomally heterozygous individuals, thus acting as an effective isolation mechanism (revision in King 1993), or by reducing recombination rates and extending the effects of linked isolation genes (Rieseberg 2001; Livinsgtone and Rieseberg 2004). Tiger beetles, in particular members of the subtribe Cicindelina, are suitable taxa to explore the link between chromosomal rearrangements and great species diversity. Cytogenetics is still a poorly developed discipline in tiger beetles, with very few cicindelid species karyotyped (Serrano and Galián 1998; Galián and Hudson 1999; Proença et al. 1999; Galián et al. 2002, 2007; Proença et al. 2002a, b, 2005; Zacaro et al. 2004), not exceeding about $4 \%$ of more than 2415 described taxa (Wiesner 1992; Lorentz 2005; Pearson and Cassola 2005). Within the more recent tribe Cicindelini the generalized karyotype is made up of nine to eleven autosomal pairs of decreasing size (Galián et al. 1990), plus a sex chromosome mechanism of the $\mathrm{X}_{\mathrm{n}} \mathrm{Y}$ type, where $\mathrm{n}$ varies between 2 and 4 that forms a non-chiasmatic multivalent connected by telomeric proteins during meiosis (Giers 1977). The sex multivalent segregates all X chromosomes to one pole and the Y-chromosome to the other during first meiotic division. Multiple sex chromosomes have been found in other taxa of the tribes Cicindelini and Collyrini (Galián et al. 1990, 2002, 2007). Single systems representing secondary loss of both X-and Y-chromosomes have been described in Cylindera germanica (XY/XX) (Giers 1977), Cylindera paludosa (X0/XX) (Serrano et al. 1986), Odontocheila confusa (XY/XX) and O. nodicornis (X0/XX) (Proença et al. 2002a). On the other hand, single systems (XY/XX and $\mathrm{X} 0 / \mathrm{XX})$ have been considered as an ancestral state in the morphologically more primitive lineages, namely the tribes Megacephalini (Serrano et al. 1986; Galián and Hudson 1999; Proença et al. 2002b), Mantichorini and Omini (Galián et al. 2002).

Characterization of the number and distribution of ribosomal DNA (rDNA) genes using fluorescence in situ hybridization (FISH) provides landmarks for the construction of physical maps in comparative genomics, and is useful for phylogenetic and evolutionary studies. Galián et al. (1995) initiated molecular cytogenetic studies on tiger beetles by reporting the localization of these highly repetitive and conserved rDNA clusters in some Palearctic species of the genus Cicindela. Galian et al. (2002) showed that more primitive lineages (Manticorini, Omini and Megacephalini) have a high number of rDNA loci, located exclusively in the autosomes (three and four pairs), whereas more advanced lineages (tribes Collyrini and Cicindelini) show a lower number of rDNA loci but with a variety of localization patterns. According to overall evidence these loci may be found on the autosomes (one autosomal pair), on the heterosomes (one of the $\mathrm{X}$ chromosomes and the $\mathrm{Y}$ ) or in both types of chromosomes (one autosomal pair plus heterosomal copies lo- 
cated on one of the X chromosome) (Galián et al. 1995; Galián and Hudson 1999; Galián et al. 2002; Proença et al. 2002a, b; Proença and Galián 2003; Zacaro et al. 2004). This dynamism was exemplified by the occurrence of frequent changes of the rDNA loci between autosomes and sex chromosomes in North American species of Cicindela and related taxa (Cylindera and Cicindelidia among others) (Galián et al. 2007).

These interspecific differences are mirrored, as expected, by intraspecific differences in particular species of tiger beetles. A population study regarding the number and localization of rDNA clusters in Cicindela (Calomera) littoralis and Lophyra flexuosa showed that both species were polymorphic for these traits as a single population of each species had an rDNA localization different from all the other populations (Proença and Galián 2003). These polymorphisms provide the basis for the fixation of local chromosomal variants giving rise to local chromosomal races and the subsequent formation of karyotypic barriers to gene flow, and eventually to differentiated phylogenetic entities.

In this paper we apply fluorescence in situ hybridization with a $18 \mathrm{~S}$ ribosomal probe to six Paleartic taxa of the genera Cephalota and Cylindera with different sex chromosome systems (XO, XXY, XXXY, XXXXY), some of which were previously studied cytogenetically by Galián et al. (1995) only using silver staining. This last method may underestimate the actual number of chromosomes carrying rDNA genes as non active or seldom active NORs remain unnoticed. We shall also discuss the putative evolutionary implications of the patterns of localization and number of rDNA loci.

\section{Material and methods}

\section{Material}

Individuals belonging to the six species studied were collected in the localities listed in Table 1. Males and females were analysed in all species, although in Cephalota deserticoloides, C. circumdata and Cylindera paludosa, only males provided interpretable plates.

The specimens were identified by the authors and are deposited in the collection of the Department of Animal Biology, University of Lisbon, and in the Department of Zoology and Physical Anhropology, University of Murcia.

\section{Chromosome preparations}

Karyological analyses were carried out on gonads dissected from beetles anaesthetised with ethyl-acetate. Testes and ovaries were given a hypotonic treatment in distilled water and fixed using fresh ethanol-acetic acid solution (3:1) for $1 \mathrm{~h}$, with several changes of the fixative solution during the next day and were kept at $-20{ }^{\circ} \mathrm{C}$ until studied. Squashes were made on a slide in $70 \%$ acetic acid and coverslips were removed after freezing in liquid nitrogen. The slides containing well spread mitotic and meiotic figures were aged for at least 3 days in a $37^{\circ} \mathrm{C}$ incubator. 


\section{In situ hybridization}

FISH was performed as previously described (Galián et al. 1999; Sánchez-Gea et al. 2000; Galian et al. 2007) with minor modifications. The ribosomal probe was obtained by amplification of an $18 \mathrm{~S}$ rDNA fragment as described in De la Rúa et al. (1996). Briefly, chromosome spreads were pre-treated with DNase-free RNase in $2 \times$ SSC for $1 \mathrm{~h}$ at $37{ }^{\circ} \mathrm{C}$, followed by treatment with $0.005 \%$ pepsin in $10 \mathrm{mM}$ $\mathrm{HCl}$ for $10 \mathrm{~min}$. After digestion the chromosomes were fixed with fresh paraformaldehyde in $\mathrm{NaOH} 0.1 \mathrm{~N}$, dehydrated in a graded ethanol series and air dried. The hybridization mixture containing 50\% deionized formamide, $2 \times$ SSC, $50 \mathrm{mM}$ sodium phosphate $(\mathrm{pH}=7.0), 10 \%$ dextran sulphate and $4 \mathrm{ng} / \mathrm{ml}$ of labelled probe was denatured by boiling for $3 \mathrm{~min}$ and placed on ice. The slides were heated on an $80^{\circ} \mathrm{C}$ hot plate for $5 \mathrm{~min}$. A $30 \mathrm{ml}$ aliquot of the denatured hybridization mixture was placed over the denatured slides and covered with a $22 \times 22 \mathrm{~mm}$ coverslip. The slides were then transferred to a humid chamber at $80^{\circ} \mathrm{C}$, and the temperature was allowed to drop slowly to $37^{\circ} \mathrm{C}$ for hybridization overnight. After hybridization coverslips were carefully removed and the slides were then given a stringent wash for $3 \times 5 \mathrm{~min}$ in $50 \%$ formamide, $2 \times \mathrm{SSC}$ at $37^{\circ} \mathrm{C}$. Sites of probe hybridization were detected with avidin-fluorescein isothiocyanate (FITC). The signal was amplified twice using goat anti-avidin-biotin. Slides were counterstained with propidium iodide and mounted with antifade solution to prevent the fluorescence fading away. Slides were examined with a Leitz photomicroscope and photographed with Imation colour film 100 ASA.

\section{Silver staining}

Active NORs were detected with silver according to the Howell and Black (1980) technique, with slight modifications. Two solutions were prepared, one colloidal developer containing $0.2 \mathrm{~g}$ powdered gelatine in $10 \mathrm{ml}$ distilled water and $0,1 \mathrm{ml}$ of formic acid and a solution of $50 \% \mathrm{AgNO}_{3}$, centrifuged at $13000 \mathrm{~g}$ for 5 min to separate the silver previously precipitated and kept in the dark. One part of the colloidal developer and two parts of the silver solution were placed on the slides, mixed, covered with a coverslip and incubated at $70{ }^{\circ} \mathrm{C}$ on a hot plate until the solution has turned a deep goldenbrown colour. The slides were rinsed thoroughly in distilled water, counterstained with 5\% Giemsa in phosphate buffer $\mathrm{pH}$ 6.8, washed and air-dried.

\section{Results}

Detailed karyotypes of the six species investigated have been reported previously (Serrano et al. 1986; Serrano and Collares-Pereira 1989, 1992; Collares-Pereira and Serra- 
no 1990; Galián et al. 1990) and were used for comparisons. Male and female mitotic metaphases and first and second male meiotic cells were analysed and compared to identify homology among labelled chromosomes. The karyotypes of Cephalota hispanica, C. maura and Cylindera trisignata are represented in Figure 1 to illustrate the three types of multiple sex chromosome systems. The number of rDNA carrying chromosomes varies from 2 to 4 (Table 1 ) and they are restricted to the autosomes, to the heterosomes, or are found in both types of chromosomes.

The rDNA probe hybridizes to the third autosomal pair in male and female mitotic figures of Cephalota hispanica (Fig. 2a, b) and the signal is distantly located. Meiotic figures confirm hybridization on the third autosomal bivalent (Fig. 2c, d). Second metaphase plates have one signal each, 9+ $X_{1} X_{2}$ and 9+Y (Fig. 2e, f).

Cephalota maura shows four signals in female mitotic metaphases (Fig. 2g), in two small and two medium-sized chromosomes. Male mitotic plates show signals in two small and one medium-sized element (Fig. 2h). In male diakinesis two fluorescent signals are seen in one small autosomal bivalent and one signal in the sex vesicle (Fig. $2 \mathrm{i}, \mathrm{j}$ ), most likely in one of the Xs. This is confirmed by the observation of second metaphase plates that are of two types, with 12 elements $\left(9+X_{1} X_{2} X_{3}\right.$, Fig. $\left.2 k, 1\right)$ and 2 signals, and with 10 elements $(9+Y$, Fig. $2 \mathrm{~m}, \mathrm{n})$ and one signal.

Male spermatogonial mitosis of Cephalota deserticoloides shows signals in four small chromosomes (Fig. 3a, b). Meiotic plates show two hybridization sites in the sex vesicle and one additional site in one autosomal bivalent (Fig. 3 c, d). A similar pattern is shown by Cephalota circumdata, which has signals in 4 chromosomes in male mitosis (Fig. 3e, f). First metaphase plates of this species have one autosomal bivalent and two heterosomes labelled (Fig. 3g).

A different situation is present in Cylindera trisignata, where three labelled chromosomes are observed in male mitosis. These chromosomes may correspond to 3 of the 5 heterosomes as they are of different (from medium to small) size. Female mitotic plates show four signals in one small and one medium-sized pairs (Fig. 3h, i). Male meiotic figures confirm this interpretation and show fluorescent signal in three of the five elements of the sex vesicle (Fig. 3j). This is further confirmed in second metaphase plates where two types are observed. Two signals are present in cells with $9+\mathrm{X}_{1} \mathrm{X}_{2} \mathrm{X}_{3} \mathrm{X}_{4}($ Fig. $3 \mathrm{k}, \mathrm{l})$ and one signal is present in cells with $9+\mathrm{Y}$ (Fig. 3m, n).

Cylindera paludosa is the only species studied without multiple sex chromosomes (males are $n=7+\mathrm{XO}$ ). Observations here made in individuals from Salinas de Pinilla agree with the description of the karyotype (Galián et al. 1990) in individuals from Albatera, and the autosomal localization of the rDNA sites obtained from individuals from Hellin (Galián et al. 1995).

Silver staining was performed for $C$. hispanica, C. circumdata and C. trisignata to locate active NORs in interphase nuclei. $C$. hispanica and $C$. circumdata showed silver precipitates outside the condensed sex vesicle in interphase nuclei (Fig. 4 a, b), and $C$. trisignata showed silver precipitates inside the sex vesicle (Fig. 4c). 


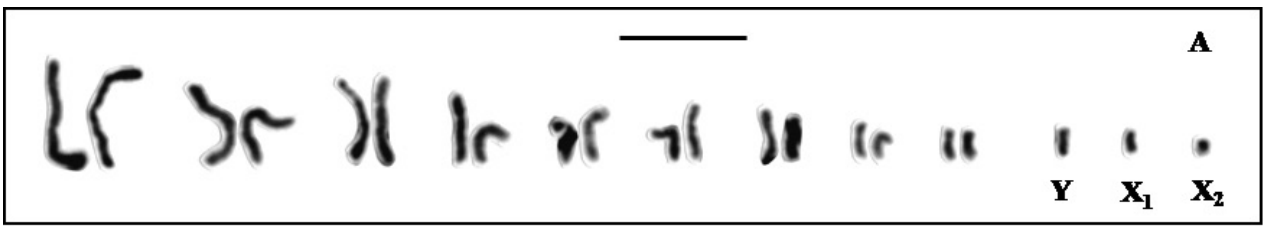

$\mathbf{B}$

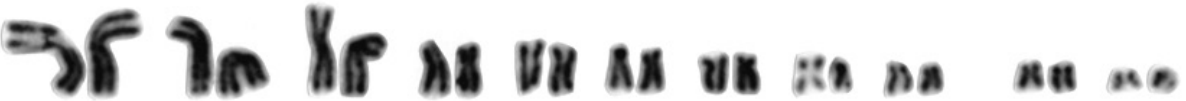

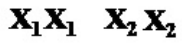
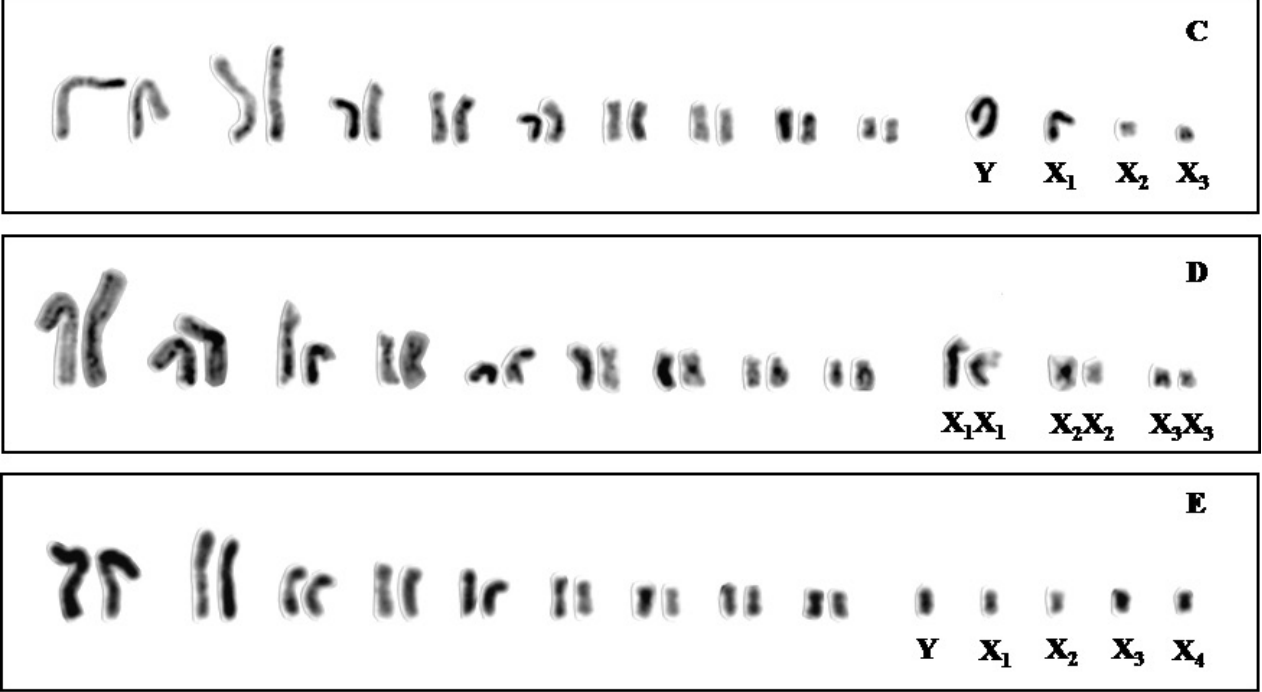

\section{F

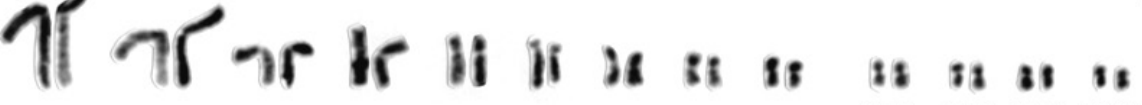 $\begin{array}{llll}\mathbf{x}_{1} \mathbf{x}_{1} & \mathbf{x}_{2} \mathbf{x}_{2} & \mathbf{x}_{3} \mathbf{x}_{3} & \mathbf{x}_{4} \mathbf{x}_{4}\end{array}$}

Figure Ia-f. Standard karyotypes of $\mathbf{a} C$. hispanica male b $C$. hispanica female c $C$. maura male $\mathbf{d} C$. maura female e C. trisignata male and $\mathbf{f} C$. trisignata female. Bar $=5 \mu \mathrm{m}$.

\section{Discussion}

Detection of rDNA sites by fluorescence in situ hybridization

The results for Cylindera paludosa corroborate previous findings (Galián et al. 1995) as one fluorescent signal was found in one pair of autosomes. Cephalota maura and C. deserticoloides have rDNA sites in the sex chromatin, as determined in early meiotic stages, 
Table I. Localities, male meioformula and pattern of rDNA localization for sampled species of tiger beetles.

\begin{tabular}{l|l|l|l}
\hline \multicolumn{1}{c|}{ Species } & \multicolumn{1}{c|}{ Localities } & Meioformula & Pattern of rDNA localisation \\
\hline $\begin{array}{l}\text { Cephalota (Cassolaia) } \\
\text { maura (Linnaeus 1758) }\end{array}$ & Castro Marim (Portugal) & $9+\mathrm{XXXY}$ & $\begin{array}{l}\text { (3 signals) Autosomes (2), } \\
\text { Heterosome (X) }\end{array}$ \\
\hline $\begin{array}{l}\text { Cephalota (Cephalota) } \\
\text { hispanica (Gory 1833) }\end{array}$ & Castro Marim (Portugal) & $9+\mathrm{XXY}$ & (2 signals) Autosomes \\
\hline $\begin{array}{l}\text { Cephalota (Taenidia) } \\
\text { circumdata imperialis } \\
\text { (Klug 1834) }\end{array}$ & Salinas de Pinilla (Spain) & $9+\mathrm{XXXY}$ & $\begin{array}{l}\text { (4 signals) Autosomes (2), } \\
\text { Heterosome (XY) }\end{array}$ \\
\hline $\begin{array}{l}\text { Cephalota (Taenidia) } \\
\text { deserticoloides (Codina } \\
1931 \text { ) }\end{array}$ & Albatera (Spain) & $9+\mathrm{XXXY}$ & $\begin{array}{l}\text { (4 signals) Autosomes (2), } \\
\text { Heterosome (XY) }\end{array}$ \\
\hline $\begin{array}{l}\text { Cylindera (Cylindera) } \\
\text { paludosa (Dufour 1820) }\end{array}$ & Salinas de Pinilla (Spain) & $7+\mathrm{X} 0$ & (2 signals) Autosomes \\
$\begin{array}{l}\text { Cylindera (Eugrapha) } \\
\text { trisignata (Dejean 1822) }\end{array}$ & Carrapateira (Portugal) & $9+\mathrm{XXXXY}$ & (3 signals) Heterosomes (XXY) \\
\hline
\end{tabular}

which confirms previous findings with silver staining (Galián et al. 1995). Analysis of first metaphase figures indicates that whereas $C$. deserticoloides has rDNA genes in the $Y$ chromosome and in one of the Xs, C. maura has only copies in one of the Xs. Moreover, fluorescent signals were found in two additional sites of one autosomal pair in both species, not detected previously with silver staining (Galián et al. 1995). On the other hand, in Cephalota circumdata, silver staining only detected the heterosomal copies of the rDNA genes, being the autosomal copies detected only by FISH. In Cephalota hispanica, with copies only in the autosomes and in Cylindera trisignata, with copies only in the heterosomes, silver staining and FISH gave the same results. It is therefore confirmed that the silver staining technique does not detect the actual number of chromosomes carrying NORs in tiger beetles. This is probably due to the existence of rDNA clusters that are inactive through most part of the cell cycle, remaining unnoticed. Further studies on the activity of NORs on more populations of these species are needed to assess the pattern of activity, if any, of these apparently "silent" rDNA clusters.

\section{Patterns of rDNA localization}

Four patterns of rDNA localization were found in the tiger beetles species analysed in this paper. These patterns are: i) One cluster located in each member of an autosomal pair (two signals); ii) Two clusters located in an autosomal pair and one in an $\mathrm{X}$ chromosome (three signals); iii) Three clusters located in three of the heterosomes XXY (three signals); and iv) One cluster located in each member of an autosomal pair and in two of the heterosomes, apparently one of the Xs and the $\mathrm{Y}$ (four signals). The last two patterns are described for the first time, and are added to the four previously described in the genus Cicindela and related taxa by Galián et al. (1995), Galián and 

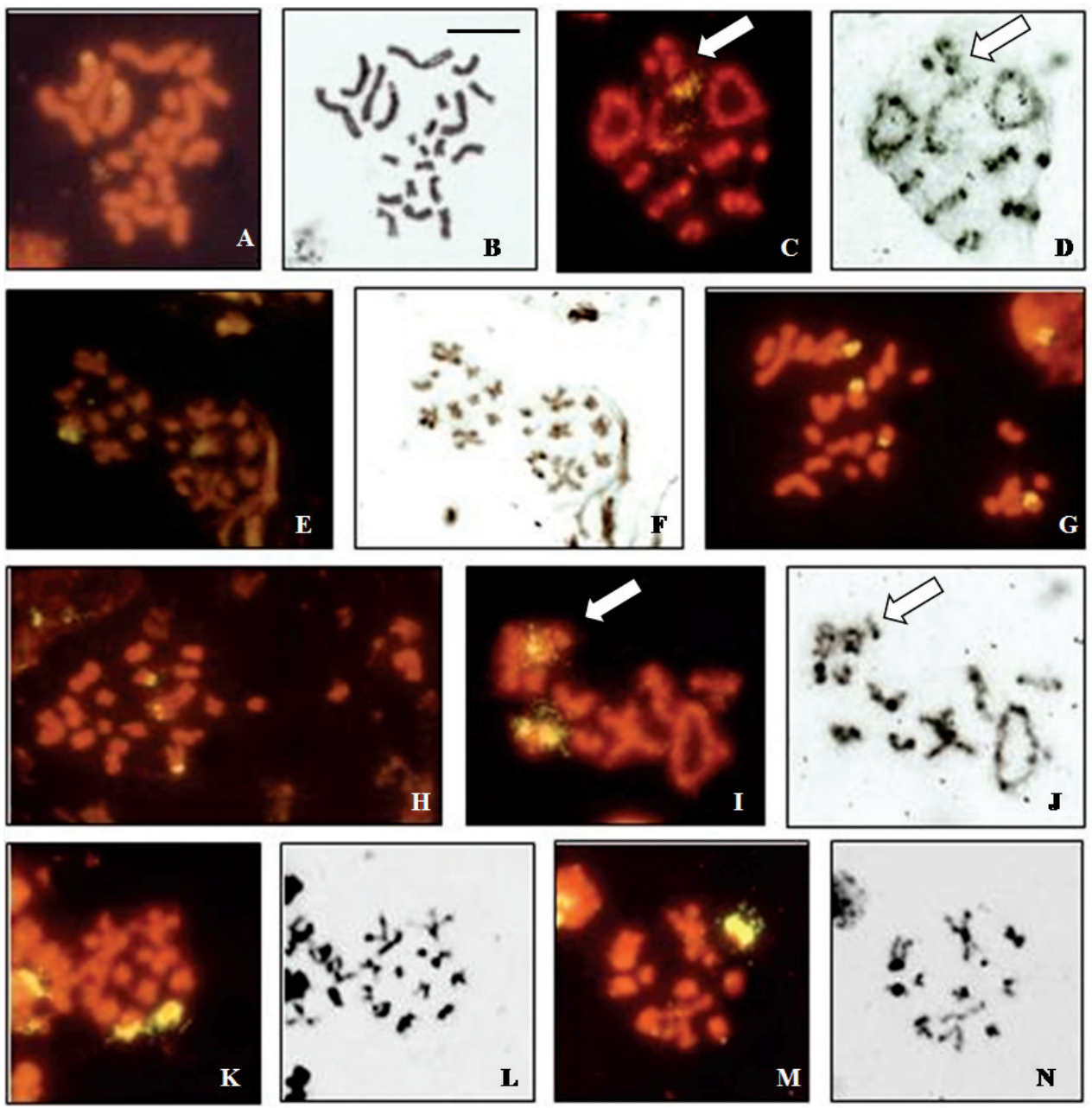

Figure 2a-n. Localization of rDNA clusters in Cicindela, revealed by in situ hybridization of the PCR amplified ribosomal probe to squashed mitotic and meiotic chromosomes. The phase contrast image of some cells is figured to the right of the fluorescence image. a, b Cicindela hispanica, female mitotic metaphase $\mathbf{c}, \mathbf{d} C$. hispanica, male metaphase I plate; $\mathrm{n}=9+\mathrm{X}_{1} \mathrm{X}_{2} \mathrm{Y}, \mathbf{e}, \mathbf{f} C$. hispanica, male metaphase II plates, $\mathrm{n}$ $=9+\mathrm{Y}$ and $\mathrm{n}=9+\mathrm{X}_{1} \mathrm{X}_{2}, \mathbf{g}$ C. maura, female mitotic metaphase $\mathbf{h}$ C. maura, male mitotic metaphase $\mathbf{i}, \mathbf{j} C$. maura, male metaphase I plate; $\mathrm{n}=9+\mathrm{X}_{1} \mathrm{X}_{2} \mathrm{X}_{3} \mathrm{Y} \mathbf{k}, \mathbf{I}$ C. maura, male metaphase II plate $\left(\mathrm{n}=9+\mathrm{X}_{1} \mathrm{X}_{2} \mathrm{X}_{3}\right) \mathbf{m}, \mathbf{n}$ C. maura, metaphase II plate $(\mathrm{n}=9+\mathrm{Y})$. Arrows indicate the sex chromatin. $\mathrm{Bar}=5 \mu \mathrm{m}$.

Hudson (1999), Proença and Galián (2003) and Galián et al. (2007). The new patterns suggest that the number and distribution of particular housekeeping genes such as the ribosomal cistrons, have undergone many changes during the radiation of the tribe Cicindelini. This dynamic pattern contrast with the relative numerical stability of the number of autosomes found in Palearctic members of the tribe (most species have nine pairs, except for Cylindera paludosa). Likewise, changes in rDNA loci are probably not coupled with changes in the number of heterosomes, as shown by the two patterns 

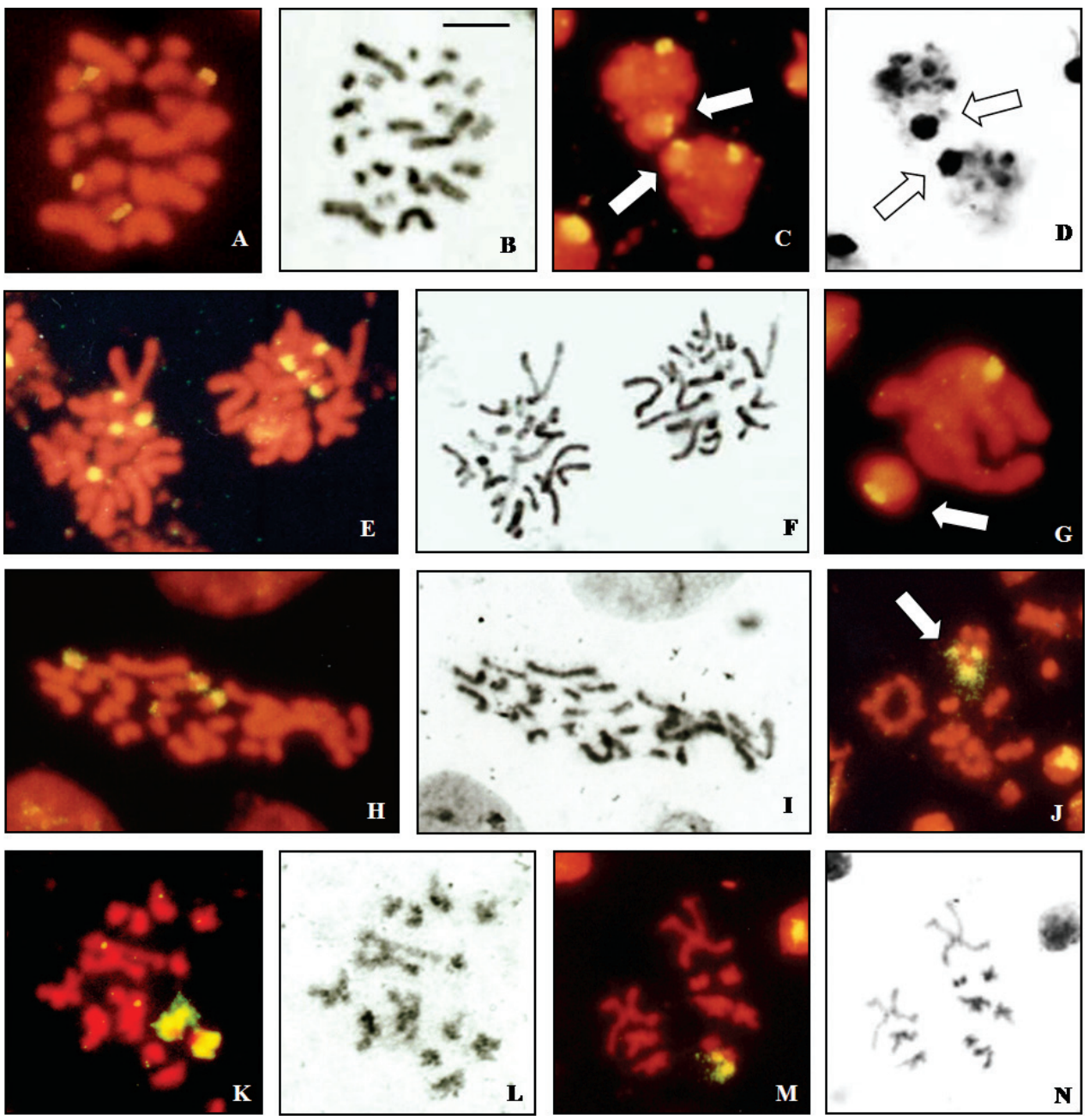

Figure 3a-n. Localization of rDNA clusters in Cicindela, revealed by in situ hybridization of the PCR amplified ribosomal probe to squashed mitotic and meiotic chromosomes. The phase contrast image of some cells is figured to the right of the fluorescence image. $\mathbf{a}, \mathbf{b} C$. deserticoloides, male mitotic metaphase c, $\mathbf{d} C$. deserticoloides, zygotene nuclei; $\mathrm{n}=9+\mathrm{X}_{1} \mathrm{X}_{2} \mathrm{X}_{3} \mathrm{Y}, \mathbf{e}, \mathbf{f} C$. circumdata, male mitotic metaphase $\mathbf{g} C$. circumdata, zygotene nuclei; $\mathrm{n}=9+\mathrm{X}_{1} \mathrm{X}_{2} \mathrm{X}_{3} \mathrm{Y} \mathbf{h}, \mathbf{i}$ C. trisignata, female mitotic metaphase $\mathbf{j}$ C. trisignata, metaphase I plate, $\mathrm{n}=9+\mathrm{X}_{1} \mathrm{X}_{2} \mathrm{X}_{3} \mathrm{X}_{4} \mathrm{Y} \mathbf{k}, \mathbf{I}$ C. trisignata, male metaphase II plate $\left(\mathrm{n}=9+\mathrm{X}_{1} \mathrm{X}_{2} \mathrm{X}_{3} \mathrm{X}_{4}\right) \mathbf{m}, \mathbf{n} C$. trisignata, male metaphase II plate $(n=9+Y)$. Arrows indicate the sex chromatin. Bar $=5 \mu \mathrm{m}$.

found in the populations of Cicindela littoralis (Proença and Galián 2003). The frequent movements of ribosomal genes from the autosomes to the multiple heterosomes (or vice-versa) during the evolution of Nearctic and Palearctic species of Cicindelini (Galian et al. 2007, this paper) is described for the first time in insects and is worth analysing in other Coleoptera and insects of other orders to test whether it is a more widespread pattern. It has been suggested that these rearrangements could be one of the causes of the great species diversity in this tribe (Galián et al. 2007). A possible 

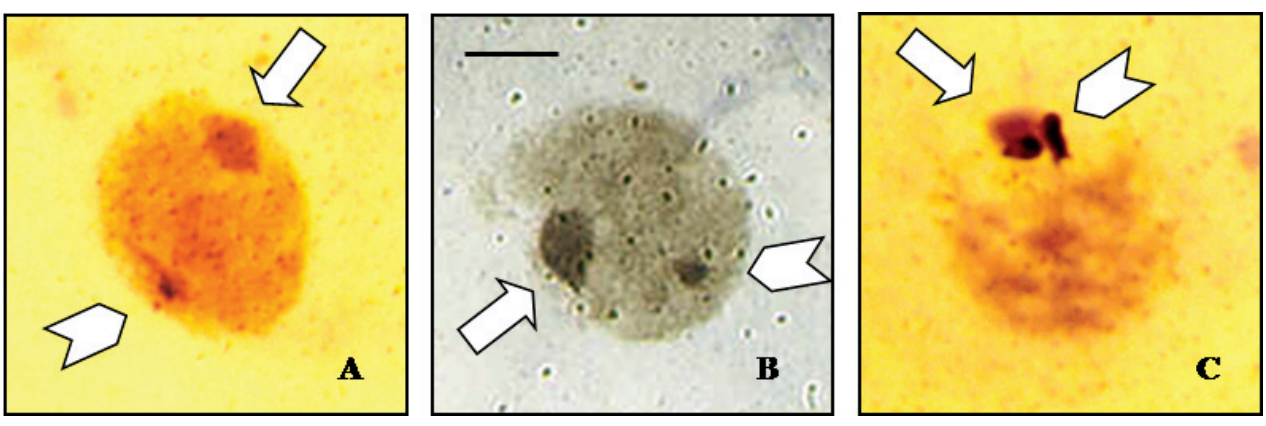

Figure 4a-c. Silver staining of meiotic nuclei, showing nucleolar activity on the autosomes of a $C$. hispanica, and $\mathbf{b} C$. circumdata, and on the sex chromosomes of $\mathbf{c} C$. trisignata. Arrows indicate the sex chromatin and arrowheads point the nucleolar active sites. Bar $=5 \mu \mathrm{m}$.

origin of these changes is the occurrence of transposable elements that jump from one part of the genome to another within and between chromosomes (leaving or not copies on the original site) with special preference for the rDNA sites, as reported by Granger et al. (2004) for Caenorhabditis elegans through insertional mutagenesis experiments. Mariner-like transposable elements were successfully amplified in C. maura (Proença and Galian preliminary results).

Species of the more primitive lineages such as Amblycheila, Megacephala and Mantichora have from two to four autosomal pairs carrying ribosomal genes (Galián and Hudson 1999; Galián et al. 2002; Proença et al. 2005). This fact suggests that within the Palearctic species of the tribe Cicindelini rDNA genes have jumped from the autosomes to the heterosomes, either leaving copies in the autosomes, as in Cicindela litorallis (Proença and Galián, 2003), Cephalota maura, C. deserticoloides, and C. circumdata (this paper), or not as in Myriochila melancholica (Galián et al. 1995). The same hypothesis was also put forward for the Nearctic species of Cicindela subgenus Cicindelidia (Galian et al. 2007), as C. flohri, C. nebuligera, C. obsoleta, C. rufiventris and C. sedecimpunctata have the rDNA loci on one autosomal pair whereas $C$. aterrima, $C$. nigrocoerulea, $C$. ocellata, $C$. roseiventris and $C$. rugatilis retain a copy on one autosomal pair and bear additional copies on one $(\mathrm{X})$ or two $(\mathrm{XY})$ heterosomes. More data on different tiger beetle lineages would test this hypothetical scenario. Whatever the nature of the mechanisms causing the marked variation of $\mathrm{rDNA}$ localization among species of Cicindelini, it is clear that these are also operating within some species, as inferred from the polymorphism found in Lophyra flexuosa and Cicindela littoralis (Proença and Galián 2003).

The results in Cylindera trisignata, $\left(\mathrm{X}_{1} \mathrm{X}_{2} \mathrm{X}_{3} \mathrm{X}_{4} \mathrm{Y}\right)$ give some clues about the origin of the fourth $\mathrm{X}$. This species has three heterosomes with ribosomal genes. This fact may support the hypothesis of a mechanism of $\mathrm{X}$ dissociation rather than the incorporation of autosomal segments into the multiple sex chromosomes system as the origin of the $4 \mathrm{X}$ condition. This last hypothesis was proposed by Collares-Pereira and Serrano (1990), Guénin (1952) and Dasgupta (1967) to explain the increase in the number of heterosomes. The fact that the heterosomes with the fluorescent signals are the $\mathrm{Y}$, the 
$\mathrm{X}_{1}$ and likely the very small $\mathrm{X}_{4}$, provides experimental support to the $\mathrm{X}$-dissociation hypothesis.

\section{Acknowledgements}

This work has been supported by Fundação para a Ciência e Tecnologia, PRAXIS XXI/ BD/15986/98, Portugal and Project No CLG2008-03628 of the DGI of the Spanish Ministry of Science and Innovation. Thanks are due to Elena Martínez-Navarro for technical assistance, and José Fermín Sánchez-Gea and Pilar De la Rúa for useful comments and discussion. Prof. Bárbara Fernández is acknowledged for facilitating the use of the fluorescence microscope.

\section{References}

Collares-Pereira MJ, Serrano ARM (1990) Karyological analysis of Cylindera trisignata (Latreille, Dejean, 1822) from Portugal (Coleoptera, Cicindelidae). Genetica 82: 79-83. doi:10.1007/BF00124635

Coyne JA, Orr HA (2004) Speciation. Sinauer Associates, Sunderland, Mass., 545 p.

Dasgupta J (1967) Meiosis in male tiger beetle Cicindela catena Fabr. (Cicindelidae: Coleoptera). Science Culture 33: 491-493.

De la Rúa P, Serrano J, Hewitt GM, Galián J (1996) Physical mapping of rDNA genes in the ground beetle Carabus and related genera (Coleoptera: Carabidae). Journal of Zoological Systematics and Evolutionary Research 34: 95-101.

Futuyma DJ, Mayer C (1980) Non-allopatric speciation in animals. Systematic Zoology 29: 254-271. doi:10.2307/2412661

Galián J, De la Rúa P, Serrano J, Juan C, Hewitt, M (1999) Phylogenetic relationships in West Mediterranean Scaritina (Coleoptera, Carabidae) inferred from mitochondrial COI sequences and karyotype analysis. Journal of Zoological Systematics and Evolutionary Research 37: 85-92. doi:10.1046/j.1439-0469.1999.372105.x

Galián J, Hogan JE, Vogler AP (2002) The origin of multiple sex chromosomes in tiger beetles. Molecular Biology and Evolution 19: 1792-1796.

Galián J, Hudson P (1999) Cytogenetic analysis of Australian tiger beetles (Coleoptera: Cicindelidae): chromosome number, sex-determining system and localisation of rDNA gene. Journal of Zoological Systematics and Evolutionary Research 37: 1-6. doi:10.1046/j.14390469.1999.95095.x

Galián J, Ortiz AS, Serrano J (1990) Karyotypes of nine species of Cicindelini and cytotaxonomic notes on Cicindelinae (Coleoptera, Carabidae). Genetica 82: 17-24. doi:10.1007/ BF00057669

Galián J, Serrano J, De la Rúa P, Petitpierre E, Juan C (1995) Localisation and activity of rDNA genes in tiger beetles (Coleoptera: Cicindelidae). Heredity 74: 524-530. doi:10.1038/ hdy. 1995.74 
Galián J, Proença SJR, Vogler AP (2007) Evolutionary dynamics of autosomal-heterosomal rearrangements in a multiple-X chromosome system of tiger beetles (Cicindelidae). BMC Evolutionary Biology 7: 158. doi:10.1186/1471-2148-7-158

Giers E (1977) Die Nicht-Homologen-Assoziation multipler Geschlechtschromosomen in der Spermatogenese von Cicindela hybrida (Coleoptera). Ph.D. Dissertation, University of Münster, Münster, 87p. [In German]

Granger L, Martin E, Segalat L (2004) Mos as a tool for genome-wide insertional mutagenesis in Caenorhabditis elegans: results of a pilot study. Nucleic Acids Research 32:e117. doi:10.1093/nar/gnh111

Guénin HA (1952) Hétérochromosomes de Cicindèles. Revue Suisse de Zoologie 59: 277-282. Howell WM, Black DA (1980) Controlled silver-staining of nucleolus organizer regions with a protective colloidal developer: 1-step method. Experientia 36: 1014. doi:10.1007/ BF01953855

King M (1993) Species evolution the role of chromosome change. Cambridge University Press, Cambridge, 336 pp.

Livingstone K, Rieseberg L (2004) Chromosomal evolution and speciation: a recombinationbased approach. New Phytologist 161: 107-112. doi:10.1046/j.1469-8137.2003.00942.x

Lorenz W (2005) Systematic list of extant ground beetles of the world. (Insecta Coleoptera "Geadephaga": Trachypachidae and Carabidae incl. Paussinae, Cicindelinae, Rhysodinae). Second Edition. Published by the author, Tutzing, 530 p.

Pearson DL, Cassola F (2005) A quantitative analysis of species descriptions of tiger beetles (Coleoptera: Cicindelidae), from 1758 to 2004, and notes about related development in biodiversity studies. Coleopterists' Bulletin 59: 184-193.

Proença SJR, Galián J (2003) Chromosome evolution in the genus Cicindela: Physical mapping and activity of rDNA loci in the tiger beetles species Cicindela littoralis and C. Flexuosa. Journal of Zoological Systematics and Evolutionary Research 41: 227-232. doi:10.1046/ j.1439-0469.2003.00216.x

Proença SJR, Serrano ARM, Collares-Pereira MJ (1999) First record on the cytotaxonomy of cicindelids (Insecta, Coleoptera) from an Afrotropical region. Caryologia 52: 37-47.

Proença SJR, Serrano ARM, Collares-Pereira MJ (2002a) Cytogenetic variability in genus Odontocheila(Coleoptera, Cicindelidae): karyotypes, C-banding, NORs and localisation of ribosomal genes of $O$. confusa and O. nodicornis. Genetica 114: 237-245. doi:10.1023/A:1016221430207

Proença SJR, Serrano ARM, Collares-Pereira MJ (2002b) An unusual karyotype with low chromosome number in Megacephalini, a basal group of tiger beetles (Coleoptera, Cicindelidae): cytogenetic characterisation by C-banding and location of rDNA genes. Hereditas 137: 202-207. doi:10.1034/j.1601-5223.2002.01684.x

Proenca SJR, Collares-Pereira MJ, Serrano ARM (2005) Chromosome evolution in tiger beetles: Karyotypes and localization of 18S rDNA loci in Neotropical Megacephalini (Coleoptera, Cicindelidae). Genetics and Molecular Biology 28: 725-733. doi:10.1590/S141547572005000500012

Rieseberg LH (2001) Chromosomal rearrangements and speciation. Trends in Ecology and Evolution 16: 351-358. doi:10.1016/S0169-5347(01)02187-5 
Sánchez-Gea JF, Serrano J, Galián J (2000) Variability in rDNA loci in Iberian species of the genus Zabrus (Coleoptera: Carabidae) detected by fluorescence in situ hybridization. Genome 43: 22-28.

Serrano ARM, Collares-Pereira MJ (1989) Cytotaxonomic study of Cephalota hispanica (Gory, 1833) and Spiralia maura (Linnaeus, 1758), two cicindelids from Portugal (Coleoptera). Genetica 79: 69-75. doi:10.1007/BF00056067

Serrano ARM, Collares-Pereira MJ (1992) Further analysis of the cytotaxonomy of tiger beetles (Coleoptera: Cicindelidae) from South Portugal. Nucleus 35: 19-24.

Serrano J, Galián J (1998) A review of karyotypic evolution and phylogeny of carabid beetles (Coleoptera, Carabidae). In: Ball GE, Casale A (Eds) Phylogeny and Classification of Caraboidea. Museo Regeonale di Scienze Naturali Torino, 191-228.

Serrano J, Galián J, Ortiz A (1986) Cicindelid beetles without multiple sex chromosomes (Coleoptera, Caraboidea). Canadian Journal of Genetics and Cytology 28: 235-239.

Spirito F (1998) The role of chromosomal change in speciation. In: Howard DJ, Berlocher SH (Eds) Endless forms: species and speciation. Oxford University Press, Oxford, 320-329.

White MJD (1978) Modes of Speciation. Freeman, San Francisco, 455 p.

Wiesner J (1992) Checklist of the Tiger Beetles of the World. Verlag Erna Bauer, Keltern, 364 pp. Zacaro AA, Proenca SJR, Lopes-Andrade C, Serrano ARM (2004) Cytogenetic analysis of Ctenostomini by C-banding and rDNA localization and its relevance to the knowledge of the evolution of tiger beetles (Coleoptera: Cicindelidae). Genetica 122: 261-268. 
